\title{
Life Table Characteristics of the Two Spotted Spider Mite Tetranychus urticae Koch treated with Certain Acaricides
}

\author{
Badriea A. EL-Esnawy \\ Plant Protection Research Institute, Agricultural Research Center, Giza, Egypt
}

(Received: November 14, 2010)

\begin{abstract}
The experiment was carried out to estimate the sustainable effect of the acaricides, profenofos, hexythiazox and s.momesifen on offspring of the two spotted spider mite Tetranychus urticae Koch. The estimation was determined _. ing a combination of conventional bioassay of the tested acaricides and life table procedures of the two spotted spider mite. LC25, LC50 and LC90 of profenofos recorded 3.64, 9.90 and $66.82 \mathrm{ppm}$, respectively and $6.9,20.68$ and $: 67.2 \mathrm{ppm}$, respectively for hexythiazox; whereas they were 10.46, 57.5 and $455.8 \mathrm{ppm}$,respectively for spinomesifen. The biological aspects, developmental time of mites treated with $\mathrm{LC}_{50}$ of the tested acaricides, were followed up. Results show that the tested acaricides affected the developmental time of immature stages. Developmental time if untreated mites was achieved throughout 6.16 days; whereas it was $7.12,7.36$ and 8.88 days for mites treated with, profenofos, hexythiazox and spinomesifen, respectively. The tested acaricides showed slight effect on preoviposition period. Survivorship (Lx) varied in their chances to reach adulthood according to the tested acaricide. Fecundity $(\mathrm{Mx})$, the gross reproductive rate (GRR) and net reproductive rate (Ro) were markedly affected by the acaricides. There were no significant differences on the hatchability percentages of laid eggs by treated and untreated females and among eggs that were laid at different time throughout the laying period. Data revealed that there were no significant differences among generation time $(T)$ of treated and untreated females. Data showed that untreated mite have the highest intrinsic rate of increase $\left(\mathrm{r}_{\mathrm{m}}\right) 0.46$ per individual per day; whereas the tested acaricides, profenofos, hexythiazox and spiromesifen enhanced negative intrinsic rate of increase $-0.67,-0.74$ and -0.7 per individual per day, respectively. Data also showed that the population of the untreated mite, as finite rate of increase $(\lambda)$, increased daily by 1.58; whereas it was $0.51,0.48$ and 0.5 times for treated mite with profenofos, hexythiazox or spiromesifen respectively.
\end{abstract}

Key Words: Tetranychus urticae, Life table, Profenofos, Hexythiazox, Spiromesifen.

\section{INTRODUCTION}

The phytophagous mite Tetranychus urticae Koch, infest over 150 agricultural crops including major food, fiber crops and ornamentals (Dekeyser and Downer, 1994 and Bolland et al., 1998). T. urticae has a worldwide distribution. Recently it has described as a cause of occupational allergic disease, such as skin-prick bronchial asthma and urticaria to agricultural workers (Delgado et al., 1997)

A broad spectrum of acaricides has been applied to control the two spotted spider mite (Shokry et al., 1989, and El-adawy et al., 2001) but these acaricides were toxic to mite's predators (El-adawy et al., 2000). This lead to build up high populations of the mite causing more severs outbreaks in crops. The control strategy as regards to chemical control is to lower the pest population. The traditional bioassay, as acute mortality, gives little attention to mortality occurs in later stages.

The objective of the current work was to estimate the sustainable toxicity of certain acaricides to decrease the population of the two spotted spider mite under combination of conventional bioassay and life table procedures.

\section{MATERIALS AND METHODS}

\section{Rearing of $T$. urticae}

For establishing a colony of the two spotted spider mite. $T$. urticae in the laboratory, the technique of Guirguis et al., (1977) was employed. The original samples of the mite was collected from castor been leaves invested with the mite. The colony was reared in the laboratory of the Agricultural Research Station in Ismailia Governorate on sweet potato cuttings under constant condition of $25 \pm 2^{\circ} \mathrm{c}$ temperature and $65 \pm 5 \%$ relative humidity. Adult females of the two spotted spider mite were transferred by a fine brush to lower surfaces of a sweet potato leaves. The leaf was placed in Petri dish lined with water saturated cotton wool. The females were allowed to lay eggs for three hours and then removed. The obtained eggs were incubated until hatching.

\section{Acaricides used}

The following acaricides were used throughout the course of the study 
1 - Profenofos, formulated as Selecron $72 \%$ EC.

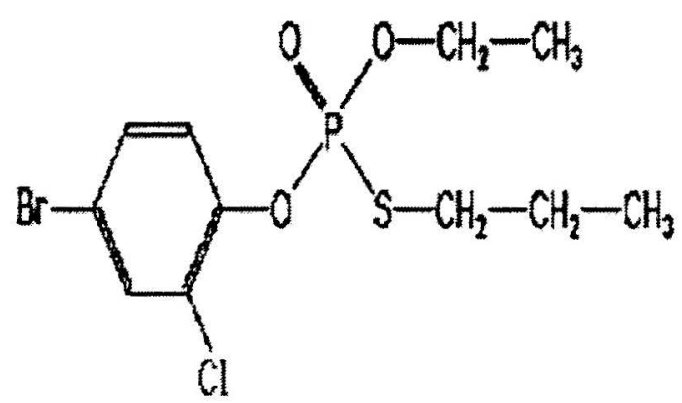

IUPAC name: $(R S)-(O-4$-bromo-2-chlorophenyl $O$ ethyl $S$-propyl phosphorothioate)

2 - Hexythiazox, formulated as Nissorun $72 \%$ EC.

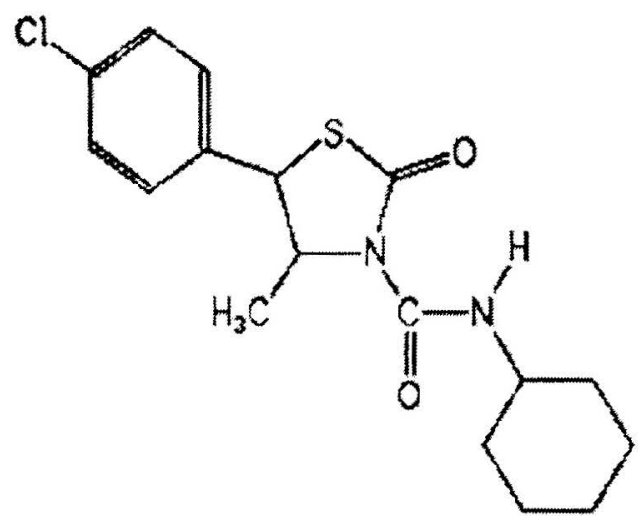

IUPAC name: (4RS,5RS)-5-(4-chlorophenyl)- $N$ cyclohexyl-4-methyl-2-oxo-1,3-thiazolidine3-carboxamide.

3 - Spinomesifen, formulated as Oberon 24\% SC.

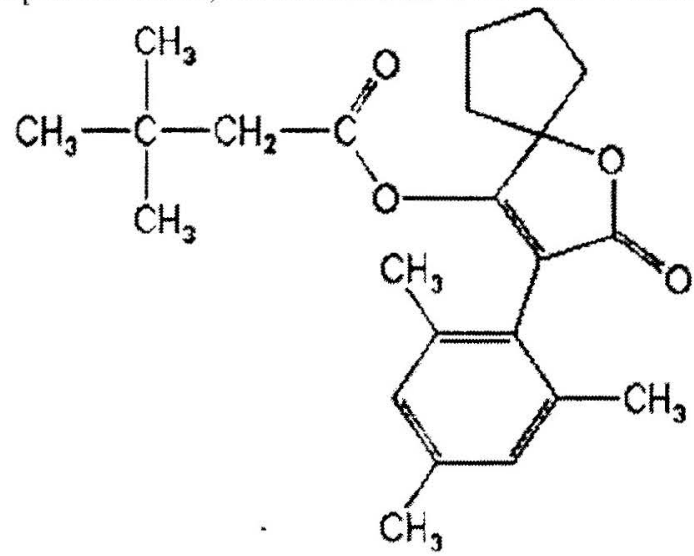

IUPAC name: 3-mesityl-2-oxo-1-oxaspiro| 4. - nem3-en-4-yl 3,3-dimethylbutanoat.

Toxicological test

Leaf disc residue film technique

This technique was followed to entmate the toxicity of the tested acaricides to the new h hathed

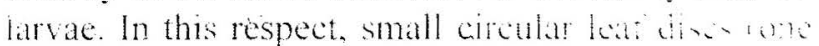
incis diameter) punched from suces nowh Late were dipped in water dilution of each of the tested acaricides for five seconds. The discs were left to dry for fifteen minutes, then placed upside down in Petri - dishes lined with water saturated cotton wool. The discs were surrounded with a light repellent tangle foot. Twenty newly hatched larvae were transferred to each disc. Each dish contained 4 discs as replicates. Five concentrations of each toxicant were tested to draw the toxicity line. Mortalities were recorded after 24 hours. Failure of mites to respond positively by leg movement following light prodding with a fine brush considered dead.

\section{Toxicological statistical analysis}

Abbot's formula (1925) was used to get correction for natural mortality. The toxicity lines were statistically analyzed according to the method described by Finney (1952). LC25, LC50 and LC90 levels of each of the three tested acaricides were calculated.

\section{Life table procedures Preparation}

Leaf discs (one inch diameter) of sweet potato leaves were dipped in water dilution of each of the testepd acaricides at $\mathrm{LC}_{50}$ for five seconds. The discs were left to dry for 15 minutes, then placed upside down in Petri - dishes lined with water saturated cotton wool. The dises were surrounded with a tangle foot. Each dish contained 5 discs. Eighty dishes were used for each treatment. Only one newly hatched larva was transferred to each disc. The same former steps were followed with untreated leaf dises as a control. Each mite was transferred to a new leaf disc every 14 days until it died. Just before female emergency, two males from the main colony were added to each leaf disc to assure mating.

Immature developmental stages of the two spotted spider mite

The steps were performed at $25^{\circ} \mathrm{C}$. Observations have been carried out every eight hr to determine the duration for each stage. The sex ratio was calculated. The deposited eggs were daily counted and then destrosed except those which were laid on the first day and every five days later, were left to hateh. The percentage of hatchability was calculated to assure the presence or absence of any acaricides residues in the latid cegs.

\section{Life table parameters}

The parameters were constructed considering the cemales of the cohort studies. The following standard life table parameters (Bengston. 1969) were followed. Females that accidentally died were omitted from the analysis. 
Parameters' table

\begin{tabular}{|c|c|}
\hline Symbol & Befinition \\
\hline $\mathrm{X}$ & Age \\
\hline $\mathrm{L}_{\mathrm{x}}$ & Probability of an individual surviving to age $x$. \\
\hline $\mathrm{M}_{\mathrm{x}}$ & Reproductive expectation of a female at age $\mathbf{x}$ \\
\hline GRR & $\begin{array}{l}\text { Gross reproductive rate, expected total number } \\
\text { of female birth produced by a female which } \\
\text { lives through all ages. } \sum \mathrm{M}_{\mathrm{x}}\end{array}$ \\
\hline $\mathrm{R}_{\mathrm{o}}$ & $\begin{array}{l}\text { Net reproductive rate, number of daughters } \\
\text { that replace an average female in course } \\
\text { generation. } \Sigma M_{x} L_{x}\end{array}$ \\
\hline $\mathrm{T}$ & $\begin{array}{l}\text { Means generation time, mean of the period } \\
\text { over which progeny are produced. } \sum x M_{x} L_{x}\end{array}$ \\
\hline $\mathrm{r}_{\mathrm{m}}$ & $\begin{array}{l}\text { Intrinsic rate of increase, number of progeny } \\
\text { produced per unit time. } L n R_{0} / t \text {. }\end{array}$ \\
\hline$\lambda$ & Finite rate of increase \\
\hline
\end{tabular}

\section{RESULTS AND DISCUSSION}

Data presented in table (1) and fig. (1) Showed the toxicity data of the tested acaricides on newly hatched larvae. It revealed that profenofos was the most effective acaricide; whereas spiromesifen was the least toxic one based on $\mathrm{LC}$ values. $\mathrm{LC}_{50}$ of the tested acaricides were 9.9, 20.68 and $57.5 \mathrm{ppm}$ for profenofos, hexythiazox and spiromesifen; respectively. Data in the same table showed that the steepest toxicity line was that of profenofos posses the highest slope value $(1.54)$; whereas the flattest line was that of hexythiazox, which has the lowest slop value (1.41).Slop value of spiromesifen was 1.42 .

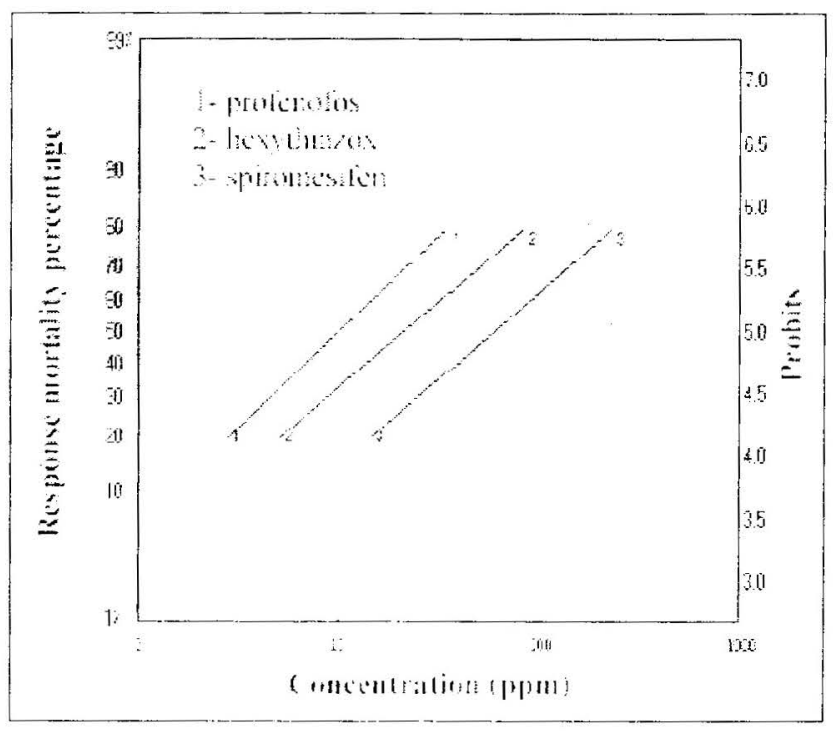

Fig. (1): Comparative suscoptibility of newly hatched larvae of the two spotted spider mite Tetranychus unticek to centain izaricides
Table (1): Toxicity of certain acaricides to newly hatched larvae of the two spotted spider mite $T$. urticae.

\begin{tabular}{lcccc}
\hline Acaricides & $\begin{array}{c}\text { LC25 } \\
(\mathrm{ppm})\end{array}$ & $\begin{array}{c}\text { LC50 } \\
(\mathrm{ppm})\end{array}$ & $\begin{array}{c}\text { LC90 } \\
(\mathrm{ppm})\end{array}$ & $\begin{array}{c}\text { Slop } \\
(\mathrm{b})\end{array}$ \\
\hline profenofos & 3.64 & 9.9 & 66.68 & 1.54 \\
\hline hexythiazox & 6.9 & 20.68 & 167.21 & 1.41 \\
\hline spiromesifen & 10.46 & 57.5 & 455.81 & 1.42 \\
\hline
\end{tabular}

\section{Immature developmental stages of the two spotted spider mite}

Developmental time, refers to the time elapsed from newly hatched larva treatment, to adult stage. Data in table (2) show that the tested acaricides had significant effects on the different aspects of development. The shortest duration time ( 6.16 days) was recorded by untreated mite; whereas the longest one ( 8.88 days) was achieved by mite that exposed to spiromesifen. The duration between treated mites by each of profenofos and hexythiazox were 7.12 and 7.36 days; respectively. No significant differences in sex ratio of treated and untreated mite. Mean value was 0.82 (female/total) for untreated mites, whereas it was $0.79,0.79$ or 0.77 (female/total) for mites treated with, profenofos, hexythiazox or spinomesifen, respectively. The tested acaricides showed slight effect on preoviposition period. It ranged between 42.2 and 48.5 hrs. The pre-oviposition period for untreated mite was $42.2 \mathrm{hrs}$, whereas it were $48.5,43.25$ and 48.0 hrs. for the treated mite with profenofos, hexythiazox or spiromesifen; respectively.

\section{Survivorship (Lx)}

Survivorship (Lx) and fecundity $(\mathrm{Mx})$ generate all the rest of life table parameters. Survivorship curve is shown in table (3) and fig. (2). Observation of (Lx) schedules revealed that the mite (newly hatched larvae) treated with the tested acaricides at LC50 were significantly varied in their chance to reach adulthood. At profenofos treatment, the chance was 39.0; at hexythiazox was 34.0 and 10.0 $\%$ for spiromesifen treatment, whereas it was $77 \%$ chance for untreated mite. It is clear that the tested acaricides sharply reduced survivorship of the two spotted spider mite. High mortalities were occurred in immature stages and chances of reaching adulthood were much lower compared with untreated mite.

\section{Fecundity (Mx)}

Based on each of the definitions, gross reproductive rate (GRR) and date presented in tat? (3), it could be stated that the mite exposed to spiromesifen had the lowest rate of deposited eggs 
Table (2): Mean duration of the immature stages of the two spotted spider mite T. urticae under certain acaricide treatments.

\begin{tabular}{|c|c|c|c|c|c|c|c|c|}
\hline \multirow{2}{*}{ Acaricides } & \multicolumn{6}{|c|}{ * Stage in hours } & \multirow{2}{*}{$\begin{array}{c}\text { Duration } \\
\text { (days) }\end{array}$} & \multirow{2}{*}{$\begin{array}{l}\text { Preoviposition } \\
\text { (hours) }\end{array}$} \\
\hline & $\mathrm{L}$. & Q.L. & P.N. & Q.P.N. & D.N. & Q. D.N. & & \\
\hline Profenofos & 34.56 & 28.8 & 28.8 & 21.12 & 28.8 & 28.8 & $7.12 \mathrm{~b}$ & 48.5 \\
\hline hexythiazox & 38.4 & 30.72 & 26.88 & 23.04 & 30.72 & 26.88 & $7.36 \mathrm{~b}$ & 53.25 \\
\hline spiromesifen & 40.32 & 36.48 & 28.8 & 34.2 & 34.56 & 38.76 & $8.88 \mathrm{a}$ & 48.0 \\
\hline Untreated & 26.4 & 23.76 & 26.4 & 18.48 & 26.41 & 26.4 & $6.16 \mathrm{c}$ & 42.2 \\
\hline L.S.D. & & & & & & & 0.642 & \\
\hline
\end{tabular}

Table (3): Demographic parameters of the two -spotted spider mite Tetranychus urticae under certain acaricide treatments.

\begin{tabular}{lcccc}
\multicolumn{1}{c}{ Parameter } & untreated & profenofos & hexythiazox & spiromesifen \\
\hline Gross Reproductive Rate(GRR) (egg/female) & 33.39 & 18.84 & 18.92 & .17 .19 \\
\hline Net Reproductive Rate(Ro) (egg/female) & 21.0 & 5.53 & 5.88 & 5.57 \\
\hline Mean generation $(\mathrm{T})$ (day) & 13.23 & 11.41 & 12.23 & 11.2 \\
\hline Intrinsic rate of increase $\mathrm{r}_{\mathrm{m}}$ (individual/day) & 0.46 & -0.67 & -0.74 & -0.7 \\
\hline Finite rate of increase $(\lambda)$ (times) & 1.58 & 0.51 & 0.48 & 0.5 \\
\hline \% of larvae surviving to adult & 77 & $39.0^{\circ}$ & 34.0 & 10.0 \\
\hline
\end{tabular}

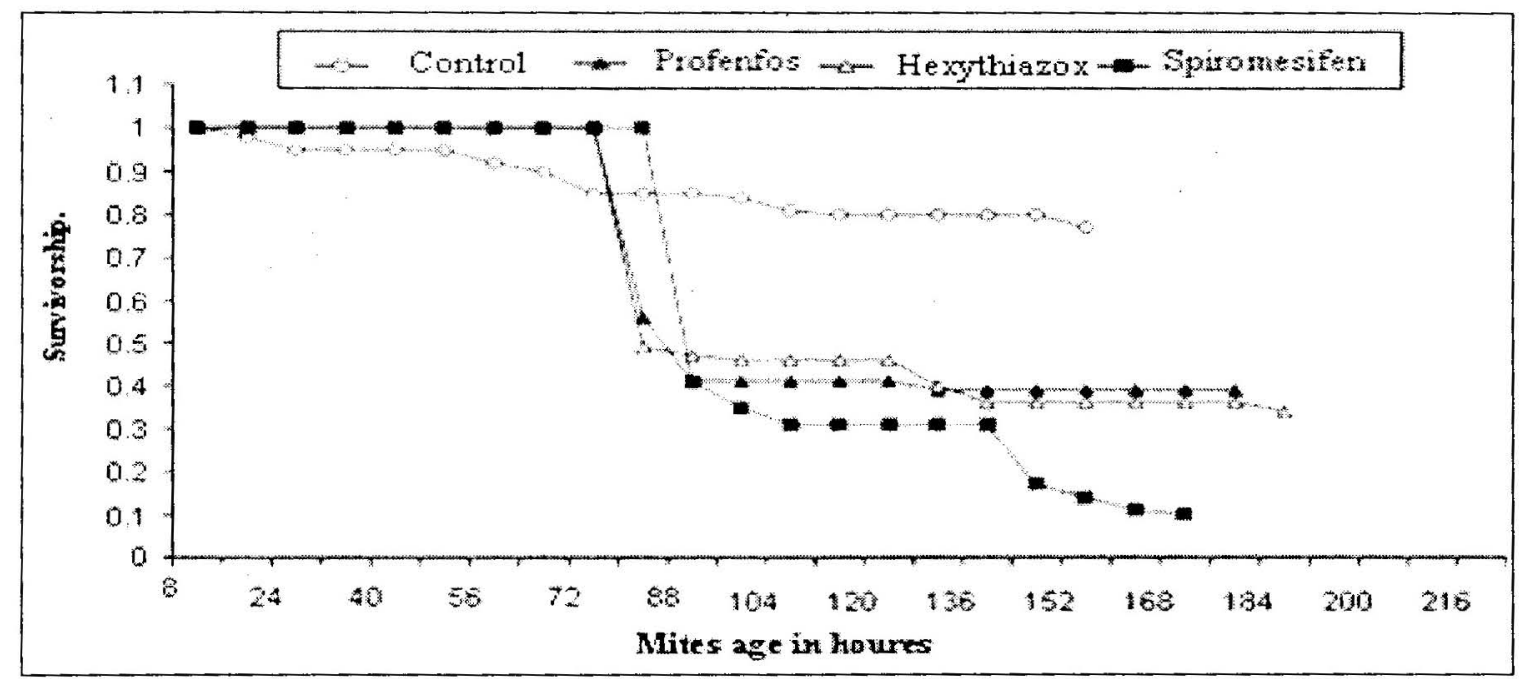

Fig. (2): Survivorship $\left(L_{X}\right)$ of immature stages the two spotted spider mite adult female treated with three acaridides.

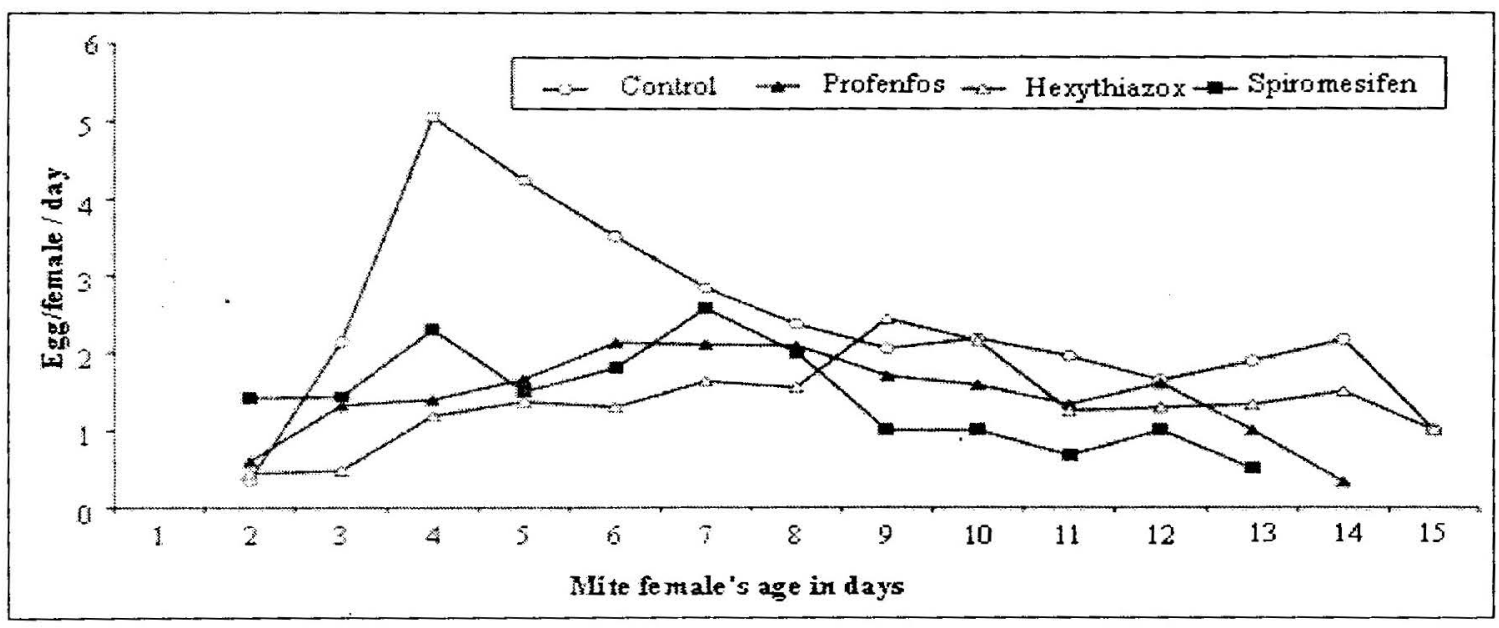

Fig. (3): Fecundity $\left(m_{X}\right)$ of the two-spotted spider mite adult female treated with three acaridides. 
(17.19 eggs/female), followed closely by profenofos (18.84 eggs/female) and hexythiazox (18.92 eggs/female), in case of the female survived to the last day of reproduction; whereas the rate was $33.79 \mathrm{eggs} / \mathrm{female}$ for untreated mite, presented $1.77,1.76$ or 1.94 times greater than that of mite treated with profenofos, hexythiazox or spiromesifen, respectively.

The reproductive peak varied according to the treatment (fig.3).It was 5.05 eggs/female at 4 -day age for untreated female, whereas it was 2.13 eggs/female at 6- days age for profenfos, 2.44 eggs/female at 9 - day age for hexythiazox and $2.5 \mathrm{eggs} / \mathrm{female}$ at 7 - days age for spiromesifen.

\section{Vet reproductive rate $(\mathrm{Ro})$}

Comparing the gross reproductive rate (GRR) and net reproductive rate (Ro) presented the effect of mortality on growth. (Ro) takes survivorship in consideration, whereas (GRR) doesn't. This means, if all untreated females live to their physiological maximum time ( 15 days), they would have laid an average of $33.39 \mathrm{eggs}$ (GRR), but because of 'mortality the average was 21.0 eggs (Ro). The same trend was among the treated mites, (table 3). GRR was $18.84,18.92$ or 17.19 eggs; whereas (Ro) was $5.83,5.88$ or 5.57 eggs for mite treated with profenofos, hexythiazox or spiromesifen; respectively. The treated females lay much fewer eggs. (Mx) presented the important role of mortality as a factor in reducing potential reproduction. There were no significant differences among the hatchability percentages of eggs laid by treated and untreated females, as well as among eggs that were laid at different time throughout the laying period. The hatchability percentage was $92 \%$ for untreated mite; whereas it was $88.93,93.63$, and $90.6 \%$ for treated mite with profenofos, hexythiazox or spiromesifen, respectively.

\section{Generation time ( $T$ )}

Data in table (3) revealed that there were no significant differences among generation time of treated and untreated females. The generation time was 13.23 days for untreated mite; whereas it was 11.41 .12 .23 or 11.2 days for treated mite with profenofos, hexythiazox or spiromesifen, respectively.

\section{Intrinsic rate of increase $\left(r_{m 11}\right)$}

Brich 1948 defined intrinsic rate natural of increase $\left(\mathrm{r}_{\mathrm{m}}\right)$ as the actual rate of increase of population under specified constant environmental condition in which space and food are unlimited when there are no mortality factor other than physiological ones. So, $\left(r_{\mathrm{m}}\right)$ depends on birth and death rates. In case of treated mites with acaricides, the value of $\left(r_{\mathrm{m}}\right)$ is determined according to the interference between acaricides as external factor and the stable physiological factors.

Data showed that untreated mites have the highest intrinsic rate of increase 0.46 per individual per day; whereas the tested acaricides, profenofos, hexythiazox and spiromesifen caused negative intrinsic rate of increase $-0.67,-0.74$ and -0.7 per individual per day, respectively.

\section{Finite rate of increase $(\lambda)$}

Data presented in table (3) showed that the population of the untreated mite increased daily by 1.58 , whereas it was $0.51,0.48$ or 0.5 times the previous day total number for treated mite with profenofos, hexythiazox or spiromesifen, respectively.

\section{CONCLUSION}

From the foregoing results, it could be seen that the three tested acaricides, profenofos, hexythiazox and spiromesifen, treated at LC50 declined the population of the two spotted spider mite. It is elear that these acaricides had sustainable toxicological effects led to negative intrinsic rates of increase.

With regards to the pervious results, it could be used at LC50 of the tested acaricides to reduce the population of the two spotted spider mite as long as using biocontrol agent throughout IPM programs. LC50 of the tested acaricides will be relatively saved compared with the full concentration of these acaricides.

\section{REFERENCES}

Abbot. W.S. 1925. A method of comparing effectiveness of an insecticide. J.Econ. Entomol., 18: 265-267.

Bengston, M. 1969. Effect of various temperatures and relative humidity on the population growth of Tetranychus urticae Koch. Queenst. Dep. Primary Ind. Div. Plant Ind. Bull. 497. 29 pp.

Birch. L.C. 1948. The intrinsic rate of natural increase on an insect population. J. Anim. Ecol.. 17: 15-26.

Bolland, II.R; Gutierrez, J. and Flechtmann. C.H.W. 1998. World Catalogue of the spider 
mite Family (Acari,Tetranychidae) Brill. Leiden.392 pp.

Dekeyser, M.A. and Downer, R.G.H. 1994. Biochemical and physiological targets for miticides. Pestic. Sci.40:85-101.

Delgado, J; J.C. Orta; Navarro, A.M.; Codo, J.; Martinez A. and Palacios R.1997.Occupational allergy in green house workers sensitization to Tetranychus urticae. Clinical and experimental Allergy, 27:640-645.

El-adawy, A.M; Youxri, H.; Ahmed Y.M.; and Tiilikalalem, K. and El-sharkawy, T.A. 2000. Estimation of general selective toxicity ratios of certain acaricides to Stethorus gilvifrons (Mulsant) and its prey Tetranychus urticae Koch. Egypt.J.AGRI. RES., 78(3): 1081-1089.

El-adawy, A. M; Ahmed, S. A. and Salem, H. A. 2001. Efficiency of certain bioacaricides against the two spotted spider mite Tetranychus urticae in cucumber. Egypt. J. Appl. Sci., 16 (3):299-306

Finney, D.J. 1952. Probit analysis - a statistical treatment of the sigmoid response curve .Cambridge university press.

Guirguis, M.W; Mohamed, I.I. and Abdel Rohman, A.M.1977. Development of resistance to Roger, Proclonol and Omite in a strain of Tetranycus arabicus Attiah in Egypt. Bull. Ent. Soc. Egypt, Econ.10:153-159.

Shokry, A; Ahmed, Y.M.; Mostafa, A.M.A. and El-Adawy, A.M.M. 1989. Susceptibility of different developmental stages of spider mite, Tetranychus urticae Koch. to certain pesticides $.3^{\text {rd }}$ Nat. Conf. of Pests \& Dis. of Veg. \& Fruits in Egypt and Arab Count. Ismailia Egypt: 409 - 420. 